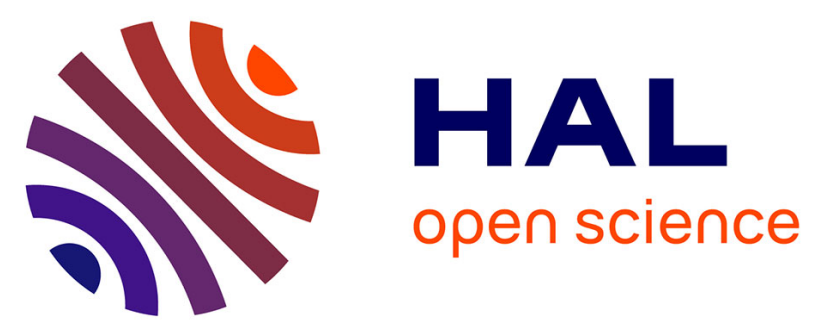

\title{
A Fused Hexacyclic Ring System: Diastereoselective Polycyclization of 2,4-Dienals through an Interrupted iso-Nazarov Reaction
}

\author{
Anne-Sophie Marques, Thibaut Duhail, Jérôme Marrot, Isabelle Chataigner, \\ Vincent Coeffard, Guillaume Vincent, Xavier Moreau
}

\section{To cite this version:}

Anne-Sophie Marques, Thibaut Duhail, Jérôme Marrot, Isabelle Chataigner, Vincent Coeffard, et al.. A Fused Hexacyclic Ring System: Diastereoselective Polycyclization of 2,4-Dienals through an Interrupted iso-Nazarov Reaction. Angewandte Chemie International Edition, 2019, 58 (29), pp.99699973. 10.1002/anie.201903860 . hal-02322633

\section{HAL Id: hal-02322633 https://hal.science/hal-02322633}

Submitted on 20 Nov 2020

HAL is a multi-disciplinary open access archive for the deposit and dissemination of scientific research documents, whether they are published or not. The documents may come from teaching and research institutions in France or abroad, or from public or private research centers.
L'archive ouverte pluridisciplinaire HAL, est destinée au dépôt et à la diffusion de documents scientifiques de niveau recherche, publiés ou non, émanant des établissements d'enseignement et de recherche français ou étrangers, des laboratoires publics ou privés. 


\title{
Fused Hexacyclic Ring System Through Interrupted iso-Nazarov Initiated Diastereoselective Domino Polycyclization of 2,4- Dienals.
}

\author{
Anne-Sophie Marques, Thibaut Duhail, Jérome Marrot, Isabelle Chataigner, ${ }^{*}$ Vincent Coeffard, ${ }^{*}$ \\ Guillaume Vincent* and Xavier Moreau*
}

\begin{abstract}
An unprecedented iso-Nazarov initiated domino polycyclization from readily available 2,4-dienals and cyclic $\alpha, \beta$ unsaturated imines is reported. This Brønsted acid-promoted reaction enables the concomitant formation of four bonds, three cycles and four contiguous stereogenic centers to yield elaborated structures in a single operation. A range of fused hexacyclic molecules is obtained in a highly diastereoselective manner.
\end{abstract}

Polycyclic architectures encompass a broad range of natural and biologically relevant products. The vast array of structural diversity and complexity reached by these molecules has fascinated synthetic organic chemists over the years. Within the context of total synthesis or synthetic chemistry methodology, considerable endeavors have been devoted to the design of efficient domino transformations ${ }^{[1]}$ that generate elaborated polycyclic tridimentional scaffolds bearing multiple stereogenic centers. Beyond that, diversity-oriented synthesis ${ }^{[2]}$ (DOS) based on readily available and versatile starting materials is one of the most attractive strategy to achieve skeletal diversity. Thus, merging domino polycyclizations with DOS approach could lead to intricate small-molecule libraries. ${ }^{[3]}$ In this context, our current interest in designing new methodologies to afford functionalized polycyclic scaffolds from simple unsaturated aldehydes ${ }^{[4]}$

$\left.{ }^{*}\right] \quad$ A.-S. Marques, T. Duhail, Dr. J. Marrot, Dr. X. Moreau Institut Lavoisier Versailles, Université de Versailles-St-Quentin-enYvelines, Université Paris Saclay, UMR CNRS 8180, 78035 Versailles cedex, France

E-mail: xavier.moreau@uvsq.fr

Prof. I. Chataigner

Normandie Univ, UNIROUEN, INSA Rouen, CNRS, COBRA (UMR 6014), 76000 Rouen, France

E-mail: isabelle.chataigner@univ-rouen.fr

Present address : Sorbonne Université, UPMC Univ. Paris 6, CNRS UMR 7616, Laboratoire de Chimie Théorique, 75005 Paris, France Dr. V. Coeffard

Université de Nantes, CNRS, Chimie Et Interdisciplinarité:

Synthèse, Analyse et Modélisation (CEISAM), UMR CNRS 6230,

Faculté des Sciences et des Techniques; 2, rue de la Houssinière,

BP 92208, 44322 Nantes Cedex 3, France

E-mail: vincent.coeffard@univ-nantes.fr

Dr. G. Vincent

Institut de Chimie Moléculaire et des Matériaux d'Orsay (ICMMO), Univ. Paris-Sud, Université Paris-Saclay, CNRS UMR 8182, 91405

Orsay cedex, France

E-mail: guillaume.vincent@u-psud.fr

Supporting information for this article is given via a link at the end of the document.((Please delete this text if not appropriate)) prompted us to investigate iso-Nazarov ${ }^{[5]}$ initiated-domino reactions (Scheme 1).

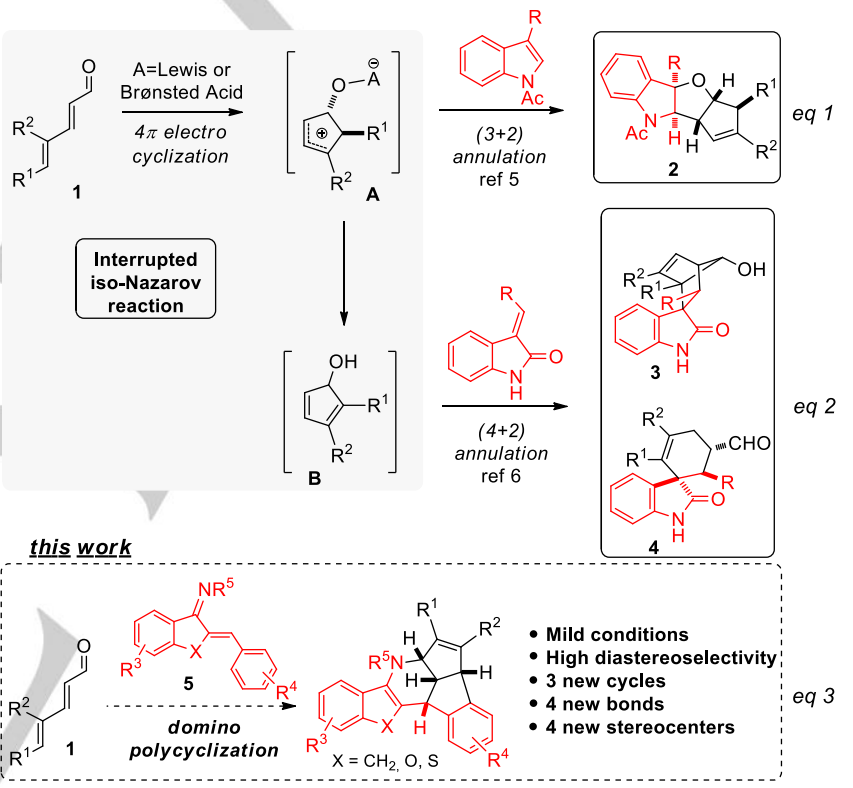

Scheme 1. Cascade polycyclizations involving an interrupted Iso-Nazarov reaction

We recently reported a $\mathrm{FeCl}_{3}$-promoted (3+2) annulation between electrophilic $\mathrm{N}$-Ac indoles and a transient oxyallyl cation $\mathbf{A}$ generated in situ from 2,4-dienals 1 leading to tetracyclic fused ring systems 2 (Scheme 1, eq 1). ${ }^{[6]}$ We then demonstrated that not only oxyallyl cations but also elusive cyclopentadienol intermediates $\mathbf{B}$ could be trapped by suitable dienophiles in DielsAlder reactions to provide bridged or spiro-fused ring sytems $\mathbf{3}$ and 4 (Scheme 1, eq 2). ${ }^{[7]}$ Herein, we report a novel domino polycyclization from 2,4-dienals enabling to enlarge the chemical space accessible through these simple substrates (Scheme 1, eq 3 ). With this purpose in mind, azadienes $\mathbf{5}$ were carrefully selected as suitable electrophilic nitrogen-containing partners. This class of compounds have been widely deployed as a privileged four-atom unit, in [4+n] annulation reactions. ${ }^{[8,9]}$ Different reactivity patterns could be envisioned. Oxyallyl cation A could be involved in $(4+3)$ or $(3+2)$ annulations with $\mathbf{5}$, while cyclopentadienol $\mathbf{B}$ could react as a diene or dienophile partner in $(4+2)$ annulations. 
We based our investigations on a model reaction between $\alpha, \beta$ unsaturated $\mathrm{N}$-tosyl imine $\mathbf{5 a}$ readily available in a two-step synthesis from indanone and 4-phenylhexa-2,4-dienal 1a (See SI for the optimisation of the reaction conditions). Gratifyingly, the use of two equivalents of the most common aqueous solution of hydrochloric acid delivered $\mathbf{6 a}$ as a unique diastereomer in an excellent $83 \%$ yield (Scheme 2). Its structure was determined by 2D NMR and confirmed by X-ray structures of few analogs. ${ }^{[10]}$ The formation of the fused benzo[4,5]pentaleno[1,6-bc]indeno[2,1e]piperidine polycylic core of $6 a$ has not been anticipated and is beyond our expectations. It arises from the formation of three new cycles, four new bonds and four contiguous stereocenters in one reaction from achiral starting materials with high levels of chemo and stereoselectivity and an impressive increase of structural complexity. Having established the optimal reaction conditions of the polycyclization sequence, we then examined the scope and limitations of this transformation.

We initially focused on the reactivity of indanone-derived unsaturated imines $\mathbf{5 b} \mathbf{b} \mathbf{5} \mathbf{f}$ decorated with a substituted aromatic ring on the benzylidene moiety. Alkyl substituents at the para position $\left(R^{4}=\mathrm{Me}, \mathrm{Et}, \mathrm{Pr}\right)$ were well tolerated to produce the desired heterocycles $\mathbf{6 b}-\mathbf{6} \mathbf{d}$ in excellent yields, still in a completely diastereoselective manner. ${ }^{[10]}$ The reaction was also applicable to substrates $\mathbf{5 e}$ and $\mathbf{5 f}$ bearing respectively an ortho $\left(R^{4}=\mathrm{Me}\right)$ or a meta substituent $\left(\mathrm{R}^{4}=\mathrm{Cl}\right)$ on the aryl ring. Noteworthy, the latter provided the corresponding hexacyclic scaffold $6 f$ as a single regioisomer in $59 \%$ yield. Next, we studied the substrate scope with respect to the substituent of the benzene ring of the indane core. $\alpha, \beta$-unsaturated imines $\mathbf{5 g} \mathbf{- 5 q}$ were conveniently transformed into the expected adducts $6 \mathbf{g}-\mathbf{6 q}$ in good to excellent yields for such multi-bond forming processes. The rapid hydrolysis of the imines $5 \mathrm{~h}, \mathbf{5 m}, \mathbf{5 0}$ and $\mathbf{5 p}$ observed upon reaction with hydrochloric acid in HFIP can explain the moderate yields observed in these cases. N-Nosyl ketimine $5 \mathrm{r}$ was also amenable to the reaction leading to $6 r$ in $54 \%$ yield. Different 2,4 dienals underwent this domino transformation affording compounds $6 \mathrm{~s}-6 \mathrm{u}$ with moderate to good yields. Noteworthy, $6 \mathrm{u}$ could be obtained from a dienal which does not possess a phenyl substituent. Finally, the reaction still proceeded smoothly when performed on 1-mmol scale using $5 \mathbf{a}$. To further challenge the scope of this sequence, aurone-based azadiene $5 \mathrm{v}$ and $\mathbf{5 w}$ were reacted with 4-phenylhexa-2,4-dienal 1a under the optimized conditions to deliver the polycyclic benzofuran motif of $6 \mathbf{v}^{[10]}$ and 6 w respectively in 33 and $53 \%$ yield. The expected benzothiophene core structure $6 x^{[10]}$ was also obtained in $32 \%$ yield along with a new unexpected tetracyclic architecture $7^{[10]}$ (14\%). The domino transformation leading to 7 differs from the previous one by the absence of an electrophilic aromatic substitution and the migration of the tosyl group. ${ }^{[11]}$

To further increase the functional group diversity of our compounds, versatile transformations of the indene-based hexacyclic derivatives were carried out (Scheme 3). We first examined the Suzuki-Miyaura cross-coupling reaction between the brominated scaffold $\mathbf{6 k}$ and phenyl boronic acid which afforded compound 8 in $72 \%$ yield. ${ }^{[12]}$

We were also able to remove the 4-nitrobenzenesulfonyl group from the nitrogen atom in $6 r$ under mild reaction conditions and the secondary amine 9 was obtained in $57 \%$ yield. ${ }^{[13]}$ Finally, the copper-catalyzed aerobic oxygenation of the benzylic methylene of the indene core of $6 \mathrm{~h}$ led to indenone 10 in $68 \%$ yield. ${ }^{[14]}$
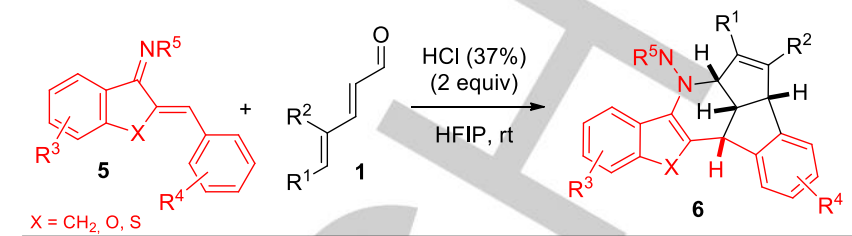

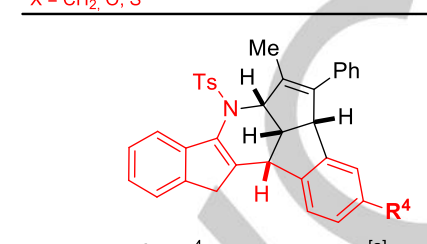

6a, $\mathrm{R}^{4}=\mathrm{H}, 83 \%(57 \%)^{[\mathrm{a}]}$

6b, $\mathrm{R}^{4}=\mathrm{Me}, 86 \%$

6c, $R^{4}=E t, 73 \%$ (X-Ray structure)

6d, $\mathrm{R}^{4}=i \operatorname{Pr}, 88 \%$

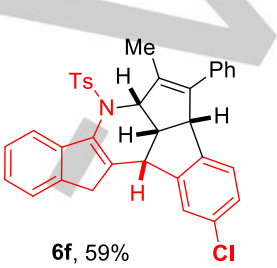

6f, $59 \%$

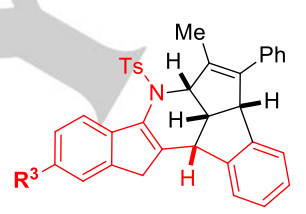

6i, $R^{3}=M e, 64 \%$

6j, $\mathrm{R}^{3}=\mathrm{Cl}, 83 \%$

6k, $\mathrm{R}^{3}=\mathrm{Br}, 82 \%$

6I, $R^{3}=F, 87 \%$

$6 \mathrm{~m}, \mathrm{R}^{3}=\mathrm{OMe}, 42 \%$

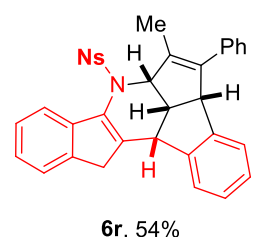

6e, $61 \%$
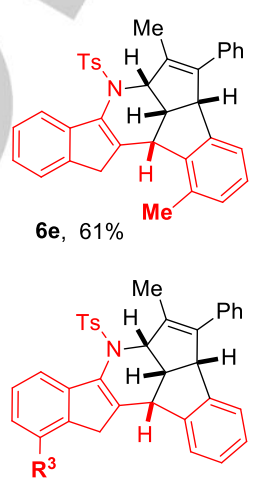

$6 g, R^{3}=M e, 56 \%$ $6 h, R^{3}=\mathrm{Br}, 45 \%$

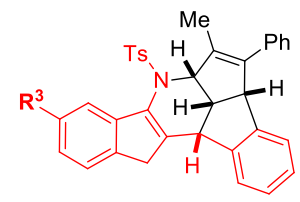

6n, $R^{3}=\mathrm{Me}, 76 \%$

6o, $\mathrm{R}^{3}=\mathrm{Cl}, 40 \%$

6q, $R^{3}=F, 60 \%$

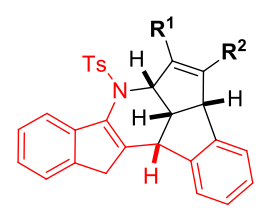

6s, $R^{1}=E t, R^{2}=P h, 77 \%$ 6t, $\mathrm{R}^{1}=i \mathrm{Bu}, \mathrm{R}^{2}=\mathrm{Ph}, 70 \%$ $6 u, R^{1}=E t, R^{2}=M e, 23 \%$
$6 \mathrm{p}, \mathrm{R}^{3}=\mathrm{Br}, 39 \%$

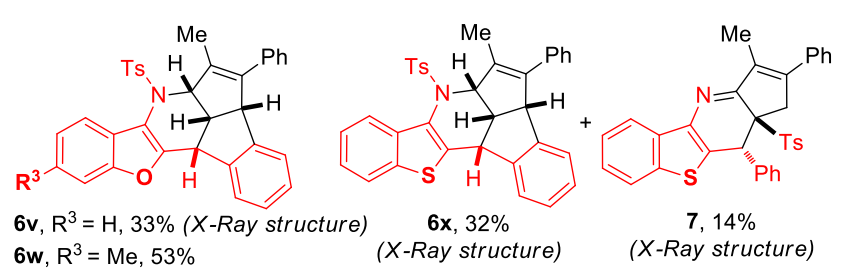

Scheme 2. Scope of the reaction for the formation of fused polycyclic scaffolds 6. General reaction conditions: dienal $1(0.2 \mathrm{mmol})$, indanone-derived unsaturated imine $5(0.1 \mathrm{mmol}), \mathrm{HCl}(37 \%)(0.2 \mathrm{mmol}), \mathrm{HFIP}(1 \mathrm{~mL})$ at $\mathrm{rt}$ for $17 \mathrm{~h}$. Yields of isolated product are reported. [a] Reaction performed on a 1mmol scale (imine 5a) 
Based on our previous work (Scheme 1, eq 2), ${ }^{[7]}$ we postulated that cyclopendienol intermediate $\mathbf{B}$ arising from dienal $\mathbf{1}$ is involved in this cryptic transformation.
$6 k$

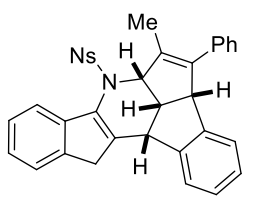

$6 r$<smiles>[3H]N1C2=C3CC4c5ccccc5C(C(c5ccccc5)=C(C)N2C)C3C41</smiles>

$6 \mathrm{~h}$

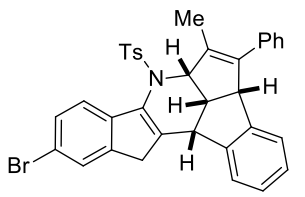

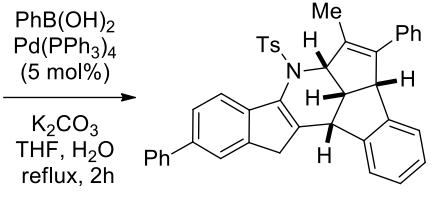

$8,72 \%$
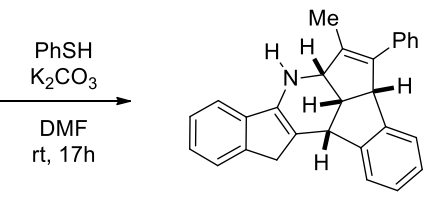

$\mathbf{9}, 57 \%$
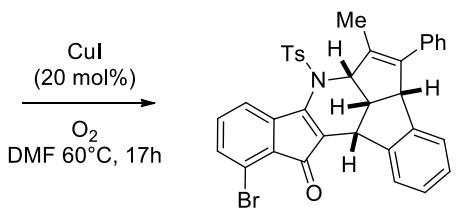

$10,68 \%$
Scheme 3. Transformations of indene-based hexacyclic derivatives. See the Supporting Information for detailed reaction conditions

To assess this hypothesis, we performed a set of control experiments (Scheme 4). According to a known procedure, ${ }^{[15]}$ the ephemeral cyclopentadienol intermediate $B\left(R^{1}=R^{2}=H\right.$, Scheme 1) was generated in situ from ferrocenium hexafluorophosphate and water under air in the presence of $\mathbf{5 a}$. Gratifyingly, in these conditions, the expected product $6 \mathbf{y}^{[10]}$ was isolated in $3 \%$ to $8 \%$ after respectively $7 \mathrm{~h}$ and $70 \mathrm{~h}$ which confirms our hypothesis. The $[4+2]$ cycloadduct $\mathbf{1 1}^{[10]}$ was obtained as the major product and unique diastereoisomer ${ }^{[16]}$ along with the corresponding hydrolyzed cycloadduct 12 and 7-aminonorbornene derivative 13 which derived from $\mathbf{1 1}$ with retention of stereochemistry. At this point, we believed that hexacycle 6y was generated from cycloadduct 11. Therefore, this spirocyclic norbornen-7-ol was engaged under the same reaction conditions affording $6 y$ in $15 \%$ yield. Under anhydrous acidic conditions, $\mathrm{HCl}$ in $\mathrm{HFIP}, 6 \mathbf{6}$ was also obtained in $1 \%$ at room temperature and $8 \%$ at $50^{\circ} \mathrm{C}$ which seems to validate our assumption. We ruled out the possibility that 6y could arise from 13 since treatment of the latter in the aforementioned conditions did not deliver 6y. ${ }^{[17]}$ DFT calculations also come to support the hypothesis of a [4+2] cycloaddition followed by the ring rearrangement of the cycloadduct (Scheme 5). ${ }^{[17]}$ The indene dienophile $\mathbf{5 z}$, bearing a mesyl group on the nitrogen atom and the unsubstituted cyclopentadienol B were chosen as realistic model substrates. The Diels-Alder process leading to the cycloadduct with the stereoselectivity observed experimentally was characterized by an activation energy of 24.3 kcal.mol ${ }^{-1}$ and an exergonicity of $8.8 \mathrm{kcal}^{\mathrm{mol}}{ }^{-1} \cdot{ }^{117]}$ Since the reaction is performed in an acidic medium, ${ }^{[18]}$ a protonated indene dienophile was envisaged and compared to the above process, involving neutral species. This expectedly showed that the reaction was more favored when implicating the protonated dienophile $\mathbf{5 z - \mathbf { H } ^ { + }}$, characterized by a lower LUMO.

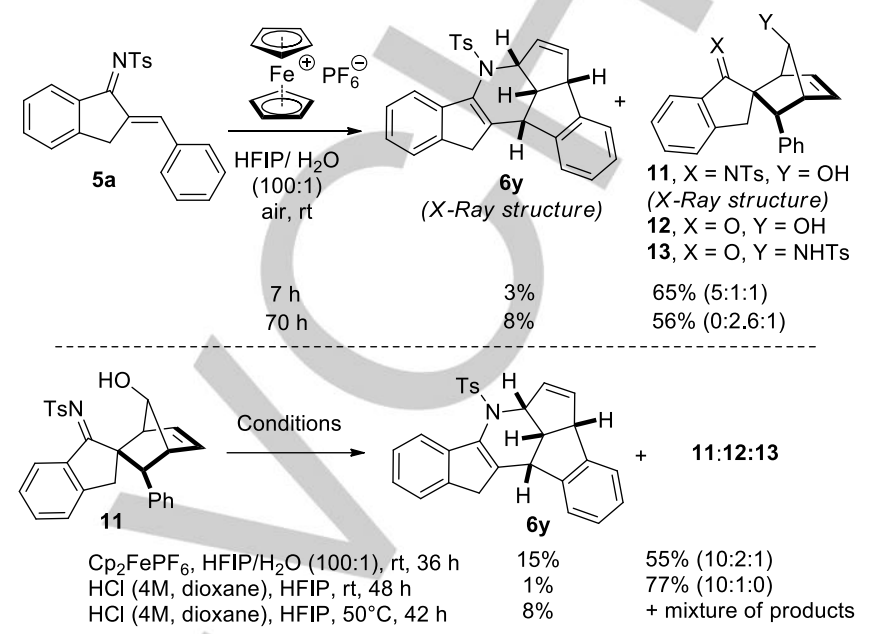

Scheme 4. Control experiments

The transition state was indeed found to be $12.1 \mathrm{kcal}^{\mathrm{mol}}{ }^{-1}$ above the reactants. A Van der Waals complex, linking the substrates, was found to be more stable than the separated substrates because of a hydrogen bond. This interaction explains why this arrangement is the most favorable. These results are fully in line with the experimental control experiments. ${ }^{[17]}$ We then turned our attention towards the ring rearrangement of cycloadduct $\mathbf{C}$ into $\mathbf{6}$. The formation of $\mathbf{1 3}$ demonstrates that the nitrogen of the imine could displace the alcohol at the 7-position of the norbornene framework with retention of stereochemistry. After cycloaddition, C would lose a water molecule and lead to the non-classical 7 norbonenyl cation $\mathbf{D} .{ }^{[19]}$ This latter is stabilized by an anchimeric assistance of the ethylenic double bond as shown by the small distances between the carbocationic center and the ethylenic carbon atoms. Its cyclisation via $\mathrm{C}-\mathrm{N}$ bond formation can then lead to cation $\mathbf{E}$. This cation seems surprisingly stable when considering its strained structure. This may however be attributed to the charge delocalization allowed in this case on the benzenic ring of the indene. Rearrangement of $\mathbf{E}$ by opening of the polycyclic structure appears to be relatively easy, even if leading to a less stable cation $F^{[20]}$ The driving force of the process would be the final aromatic electrophilic substitution ${ }^{[17]}$ which would lead, after deprotonation, to the final hexacyclic compound $\mathbf{6 z}$, stable enough to shift the possible equilibria and drive the reaction to completion. The computed values are in agreement with the experimental reaction conditions and this mechanism seems reasonable to explain the stereoselective formation of the hexacyclic adducts 6 .

In summary, we have developed an unprecedented Brønsted acid-promoted domino transformation of dienals and cyclic $\alpha, \beta-$ unsaturated imines which provides intricate fused hexacyclic ring systems in highly chemo and diastereoselective manner. This interrupted iso-Nazarov initiated process leads to the formation of 


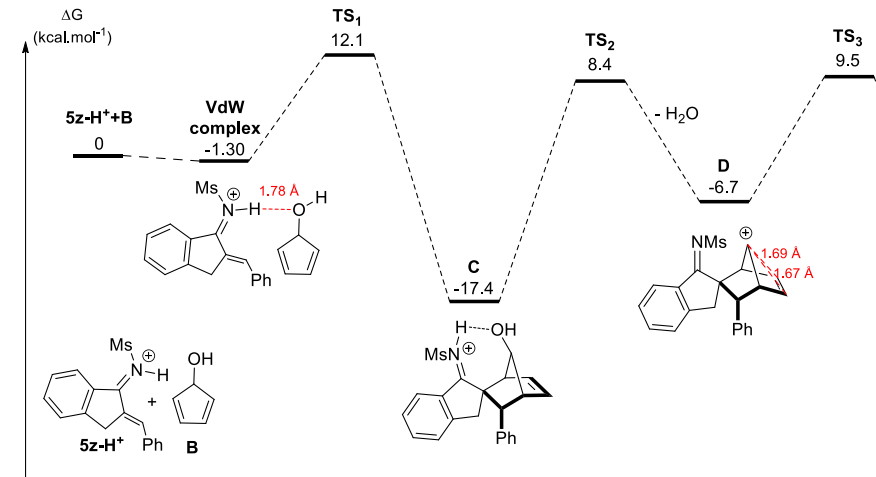

three new cycles, four new bonds and four contiguous stereocenters in one reaction from achiral starting materials and proceeds through the skeletal rearrangement of a [4+2] cycloadduct of a transient cyclopentadienol.

Scheme 5. Computed pathway for the formation of 6

\section{Acknowledgements}

A.-S. M. thanks Labex Charmmmat (ANR-11-LABX-0039) and Labex SynOrg (ANR-11-LABX-0029) for a PhD Grant. T. D. thanks Labex Charmmmat (ANR-11-LABX-0039) for a master's degree fellowship. We also thank the Agence Nationale de la Recherche (project ArDCo, number ANR-17-CE07-0050-03), Université de Versailles Saint Quentin, Université Paris-Sud and the Centre National de la Recherche Scientifique (CNRS) for financial support. We are gratefulto the CRIAAN (Saint Etienne du Rouvray, France) for the generous allocation of computer time.

\section{Conflict of interest}

The authors declare not conflict of interest.

Keywords: domino reaction • polycyclization • iso-Nazarov • pericyclic reaction $\cdot$ diversity-oriented synthesis

[1] For selected reviews, see: a) K. C. Nicolaou, D. J. Edmonds, P. G. Bulger, Angew. Chem. 2006, 118, 7292-7344; Angew. Chem. Int. Ed. 2006, 45, 7134-7186; b) A. Padwa, S. K. Bur, Tetrahedron 2007, 63, 5341-5378 c) K. C. Nicolaou, J. S. Chen, Chem. Soc. Rev. 2009, 38, 2993-3009; d) J. Poulin, C. M. Grisé-Bard, L. Barriault, Chem. Soc. Rev. 2009, 38, 3092-3101; e) E. A. Anderson, Org. Biomol. Chem. 2011, 9, 3997-4006; f) H. Pellisier, Chem. Rev. 2013, 113, 442-524; g) R. Ardkhean, D. F. J. Caputo, S. M. Morrow, H. Shi, Y. Xiong, E. A. Anderson, Chem. Soc. Rev. 2016, 45, 1557-1569.

[2] For selected reviews, see: a) S. L. Schreiber Science 2000, 287, 19641969; b) M. D. Burke, S. L. Schreiber Angew. Chem. 2004, 116, 48-60 Angew. Chem. Int. Ed. 2004, 43, 46-58; c) T. E. Nielsen, S. L.Schreiber Angew. Chem. 2008, 120, 52-61; Angew. Chem. Int. Ed. 2008, 47, 4856; d) W. R. J. D. Galloway, A. Isidro-Llobet, D. R. Spring Nat. Commun. 2010, 1, 80-86; e) C. J. O'Connor, H. S. G. Beckmann, Henning D. R. Spring Chem. Soc. Rev. 2012, 41, 4444-4456.

[3] For recent selected examples, see: a) M. C. McLeod, G. Singh, J. N. Plampin III, D. Rane, J. L. Wang, V., W. Day, J. Aubé Nat. Chem. 2014, 6, 133-140; b) C. Theunissen, B. Métayer, M. Lecomte, N. Henry, H.-C.

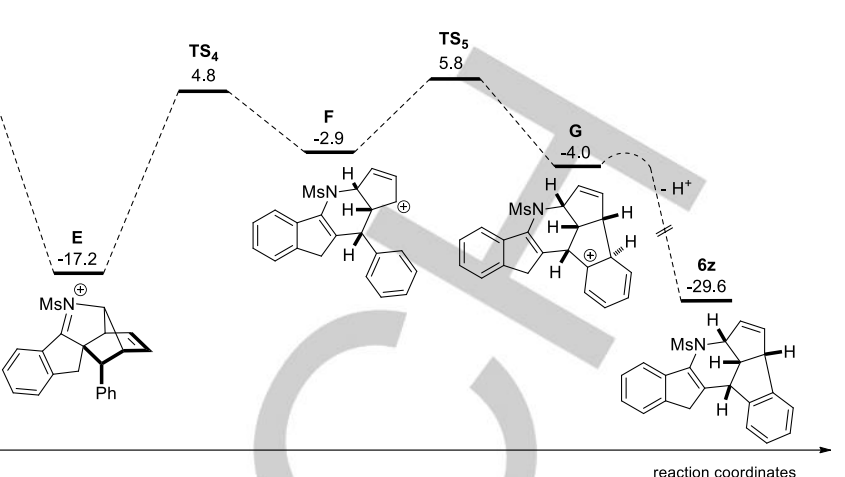

Chan, G. Compain, P. Gérard, C. Bachmann, N. Mokhtari, J. Marrot, A Martin-Mingot, S. Thibaudeau, G. Evano Org. Biomol. Chem. 2017, 15, 4399-4416; c) D. Tejedor, S. Delgado-Hernández, R. M. Carballo, R. Dapueto, G. J. Mena-Rejón, F; García-Tellado J. Org. Chem. 2017, 82, 5328-5336; d) L. Marin, R. Guillot, V. Gandon, E. Schutz, D. Lebœuf Org Chem. Front. 2018, 5, 640-647; e) S. Blouin, R. Pertschi, A. Schoenfelder, J. Suffert, G. Blond Adv. Synth. Catal. 2018, 360, 21662171.

[4] For selected publications, see: a) F. Portalier, F. Bourdreux, J. Marrot, X. Moreau, V. Coeffard, C. Greck, Org. Lett. 2013, 15, 5642-5645; b) L. Pantaine, V. Coeffard, X. Moreau, C. Greck, Org. Lett. 2015, 17, 36743677 ; c) M. Giardinetti, X. Moreau, V. Coeffard, C. Greck, Adv. Synth. Catal. 2015, 357, 3501-3506.

[5] For a review, see: M. J. Riveira, L. A. Marsili, M. P. Mischne Org. Biomol. Chem. 2017, 15, 9255-9274.

[6] A.-S. Marques, V. Coeffard, I. Chataigner, G. Vincent, X. Moreau, Org Lett. 2016, 18, 5296-5299.

[7] A.-S. Marques, J. Marrot, I. Chataigner, V. Coeffard, G. Vincent, X. Moreau, Org. Lett. 2018, 20, 792-795.

[8] For selected reviews, see: a) G. Masson, C. Lalli, M. Benohoud, G. Dagousset Chem. Soc. Rev. 2013, 42, 902-923; b) X. Jiang, R. Wang Chem. Rev. 2013, 113, 5515-5546.

[9] For selected examples of [4+n] annulation reactions of aza-dienes, see: a) Z. Shi, Q. Tong, W. W. Y. Leong, G. Zhong Chem. Eur. J. 2012, 18, 9802-9806; b) Z.-Q. Rong, M. Wang, C. H. E. Chow, Y. Zhao Chem. Eur. J. 2016, 22, 9483-9487; c) Z.-Q. Rong, L.-C. Yang, S. Liu, Z. Yu, Y.-N Wang, Z. Y. Tan, R.-Z. Huang, Y. Lan, Y. Zhao J. Am. Chem. Soc. 2017, 139, 15304-15307, d) L.-C. Yang, Z.-Q. Rong, Y.-N Wang, Z. Y. Tan, M Wang, Y. Zhao Angew. Chem. 2017, 129, 2973-2977; Angew. Chem. Int. Ed. 2017, 56, 2927-2931; e) H. Ni, X. Tang, W. Zheng, W. Yao, N. Ullah Y. Lu Angew. Chem. 2017, 129, 14410-14414; Angew. Chem. Int. Ed. 2017, 56, 2927-2931; f) K. Verma, P. Banerjee Adv. Synth. Catal. 2018 360, 3687-3692; g) Y.-N Wang, L.-C. Yang, Z.-Q. Rong, T.-L. Liu, R. Liu, Y. Zhao Angew. Chem. 2018, 130, 1612-1616; Angew. Chem. Int. Ed. 2018, 57, 1596-1600; h) Z.-H. Gao, K.-Q. Chen, Y. Zhang, L.-M. Kong, Y. Li, S. Ye J. Org. Chem. 2018, 83, 15225-15235; i) J. Chen, P. Jia, Y. Huang Org. Lett. 2018, 20, 6715-6718; j) J.-L. Li, Q.-S. Dai, K.-C. Yang, Y. Liu, X. Zhang, H.-J. Leng, C. Peng, W. Huang, Q.-Z. Li Org. Lett. 2018, 20, 7628-7632; k) K.-Q. Chen, Z.-H. Gao, S. Ye Org. Chem. Front. 2019, $6,405-409$.

[10] CCDC 1865790, 1865791, 1865792, 18657931898656 and 1898657 (compounds 6c, 6w, 7, 6v, 11 and 6y respectively) contain the supplementary crystallographic data for this paper. These data can be obtained free of charge from The Cambridge Crystallographic Data Centre.

[11] See Supporting Information for a postulated mechanism for the formation of 7.

[12] N. Miyaura, A. Suzuki Chem. Rev. 1995, 95, 2457-2483.

[13] a) T. Fukuyama, C.-K. Jow, M. Cheung Tetrahedron Lett. 1995, 36, 6373-6374; b) T. Kan, T. Fukuyama Chem. Commun. 2004, 353-359. 
[14] a) J. De Houwer, K. Abbaspour Tehrani, B. U. W. Maes Angew. Chem. 2012, 124, 2799-2802; Angew. Chem. Int. Ed. 2012, 51, 2745-2748; b) H. Sterckx , J. De Houwer , C. Mensch , I. Caretti, K. Abbaspour Tehrani, W. A. Herrebout, S. Van Doorslaer, B. U. W. Maes Chem. Sci. 2016, 7 346-357; c) H. Sterckx, C. Sambiagio, V. Médran-Navarrete, B. U. W Maes Adv. Synth. Catal, 2017, 359, 3226-3236.

[15] S. K. Allen, T. E. Lathrop, S. B. Patel, D. M. Harrell Moody, R. D. Sommer, T. C. Coombs Tetrahedron Lett. 2015, 56, 6038-6042.

[16] For the $\pi$-facial stereoselectivity of 5 -substituted cyclopentadiene in Diels-Alder cycloaddition, see : a) G. Mehta, R. Uma Acc. Chem. Res. 2000, 33, 278-286, b) B. J. Levandowski, L. Zou, K. N. Houk J. Org Chem. 2018, 83, 14658-14666.
[17] See Supporting Information for details

[18] In the case of control experiments, HF could be generated from the hydrolysis of ferrocenium hexafluorophosphate, see for example M. Deb, S. Hazra, A. J. Elias ACS Sustainable Chem. Eng. 2019, 7, 479-486.

[19] a) S. Winstein, M. Shatavsky, C. Norton, R. B. Woodward J. Am. Chem. Soc. 1955, 77, 4183-4184; b) S. Winstein, A. H. Lewin, K. C. Pande J. Am. Chem. Soc. 1963, 85, 2324-2326.

[20] The low yields of $6 \mathbf{y}$ could be explained by the lack of substituents on the cyclopentadienol to stabilize the allylic carbocation $\mathbf{F}$ in contrast to $\mathbf{6 a - w}$ 


\section{Entry for the Table of Contents}

\section{COMMUNICATION}
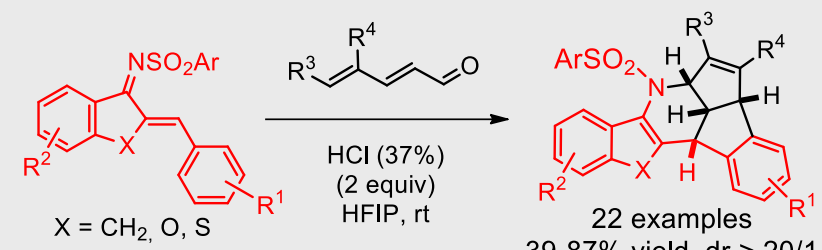

$39-87 \%$ yield, $d r>20 / 1$

An unprecedent iso-Nazarov initiated domino polycyclization is reported from readily available 2,4-dienals and cyclic $\alpha, \beta$-unsaturated imines. This Brønsted acidpromoted transformation affords original polycyclic scaffolds and allows the formation of three new cycles, four new bonds and four contiguous stereocenters in a highly diastereoselective manner.
Anne-Sophie Marques, Thibaut Duhail, Jérome Marrot, Isabelle Chataigner, Vincent Coeffard, Guillaume Vincent and Xavier Moreau

Page No. - Page No.

Fused hexacyclic ring system through interrupted iso-Nazarov initiated diastereoselective domino polycyclization of 2,4-dienals. 